\title{
Evaluation of the Effects of Acupuncture on Cerebral
} Hemodynamics in Patients Suffering from

\section{Cerebrovascular Pathology with Duplex Ultrasound Doppler Imaging}

\author{
Olga Kovalenko ${ }^{1,2}$, Maryna Chizhykova ${ }^{2,3}$ and Nataliia Dzhura ${ }^{4}$ \\ 1. Department of Family Medicine and Outpatient Care, P.L.Shupyk National Medical Academy of Postgraduate Education, Str. \\ Dorohozhytska 9, Kyiv 04112, Ukraine \\ 2. Department of Internal Medicine, State Scientific Institution "Scientific and Practical Center of Preventive and Clinical Medicine" \\ of State Administration of Affairs, Str. Verhnya, 5, Kyiv 01014, Ukraine \\ 3. Rehabilitation Center of Clinical Hospital "Feofania”, Str, Zabolotnogo, 21, Kyiv 03143, Ukraine \\ 4. Department of Functional Diagnostics, Clinical Hospital “Feofania”, Str, Zabolotnogo, 21, Kyiv 03143, Ukraine
}

\begin{abstract}
The article presents the study results of thirty patients regarding the influence of acupuncture on cerebral hemodynamics with duplex ultrasound Doppler imagines. The reliable influence of acupuncture on the blood flow parameters of vertebrobasilar and carotid vessels has been revealed. For the purpose of in-depth study of vascular response to acupuncture in the patients with various diseases, the volunteers were divided into two groups: 1 - patients, who had a stroke in anamnesis and were in the residual period (12 patients); 2 - patients who suffered from vertebrogenic disturbance of blood flow in vertebrobasilar region (18 patients). The reliable data have been obtained on the positive response to acupuncture influence of cerebral blood flow and its differences in patients with different cerebrovascular pathology.
\end{abstract}

Key words: Acupuncture, duplex ultrasound Doppler imaging, arteries and veins of head and neck.

\section{Introduction}

Pathogenetic substantiation and evidence of effective alternative non-pharmacological treatment approaches, in particular acupuncture, deserve the great attention. A number of clinical studies prove significant positive effects of acupuncture in the treatment of many diseases, namely: neck and lower back pain, joint pathology, headache, various neuropathies, rehabilitation of stroke effects, emotional and sleep disorders, etc. [1,2]. Detailed mechanisms of acupuncture effects are not fully understood yet. Taking into account the clinical and

Corresponding author: Maryna Chizhykova, Ph.D. candidate, neurologist, acupuncturist, research fields: acupuncture, pain, stroke, rehabilitation. neurophysiological achievements, it has been discovered that acupuncture effects are multilevel ones-starting with the reflex influence through the spinal segmental apparatus, as well as through the brain stem, thalamus and even the cortex, to complex neurohumoral reactions due to indirect secretion of opioid and non-opioid peptides [3-5]. Recently, the world has come up with the research that proves the presence of the PVS (primary vascular system), which may be an organic substrate of acupuncture [6-8]. However, the specificity and high individual orientation of acupuncture method complicates the implementation of standardized large-scale studies [9, 10]. Therefore, as opposed to pharmacological dual controlled trials, the results of acupuncture effects are often perceived as placebo. Thus, the neuroimaging of 
acupuncture effects in "real time" with the help of non-invasive diagnostic equipment has long attracted the attention of researchers [11]. K. Kathleen, V. Napadow and other researchers have found a reaction of the cerebral cortex with fMRI (functional magnetic resonance imaging) to stimulate the points LI4, ST36, LV3 as the most common in the treatment of pain syndromes. The changes in the cerebral cortex after acupuncture treatment of carpal tunnel syndromes have also been found [12]. S. Takayama and others [13-17] have proved the reliable effect of acupuncture at points ST36 and LV3 on blood flow rates in peripheral, retrobulbar and mesenteric vessels. Acupuncture stimulation of points GB21, ST36, PC6 showed positive microcirculation changes [18, 19]. In Ukraine the studies have also been conducted in order to determine the reliable impact of acupuncture at GV20, TE21, GB20 points on arterial brachiocephalic blood flow [20].

A lot of work is devoted to the standards of studying the arterial blood circulation with duplex ultrasound Doppler imaging [21-23]. The study of venous blood flow of head and neck is somewhat hampered due to technical complexity and lack of evaluation criteria [23-25], although some work on this issue already appears, in particular, devoted to the features of venous outflow in the patients with multiple sclerosis [26, 27].
Since the problem evidence of acupuncture effects on the vessels remains relevant and requires further study, we set the goal to investigate the effect of the acupuncture session on vertebrobasilar and carotid blood flow in the patients with different cerebrovascular pathology with duplex ultrasound Doppler imaging.

\section{Material and Methods}

To address this goal, we examined 30 volunteers, among whom 24 patients were treated at the Departments of General Neurology, Vascular Neurology and Pain Center in the clinical hospital Feofaniya. Six of the volunteers were "Feofaniya" employees.

The mean age of the group shown in Fig. 1 was 61.0 \pm 13.27 years, among them 18 females (mean age $-59.2 \pm 14.8$ years), males -12 (mean age was $63.7 \pm 9.9)$.

Twelve patients had a stroke in anamnesis and were in residual period, 18 patients suffered from vertebrogenic disturbance of blood flow in vertebrobasilar region. A duplex ultrasound Doppler imaging of extracranial brachiocephalic vessels, as well as transcranial duplex scans of vessels, was performed on an ultrasonic premium class "HI VISION Ascendus" (Hitachi, Japan) with linear transducer L73S (9.0-4.0 MHz) and cardiovascular transducer S70

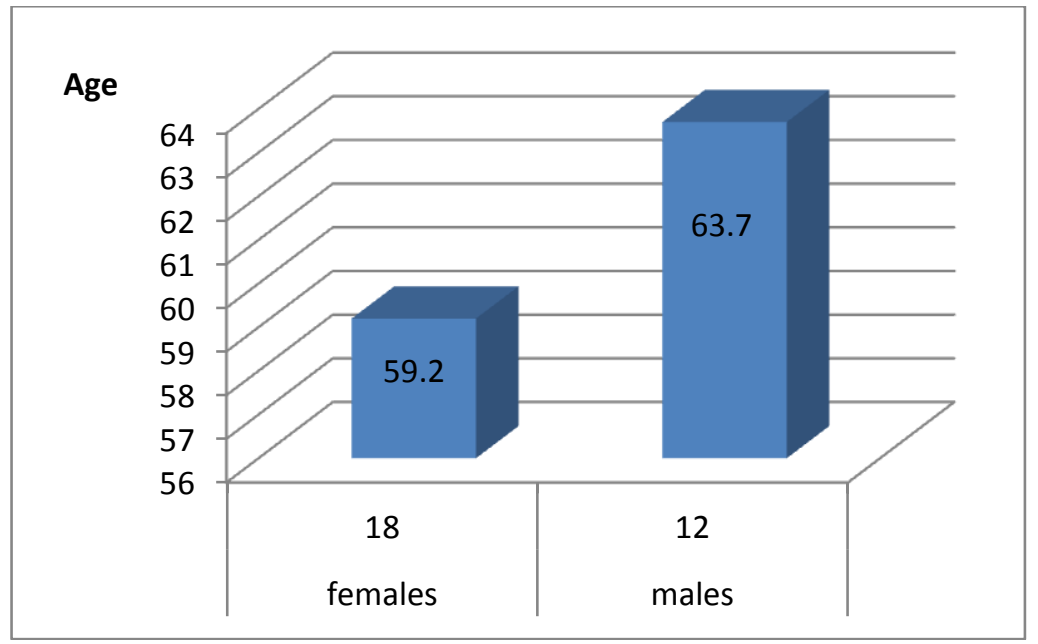

Fig. 1 Distribution of the study group by age and sex. 
(5.0-1.0 MHz) and S50A (4.0-2.0 MHz) according to the standard protocol with in-depth study of venous blood flow (v.vertebralis and v.Rosenthal).

The following calculations were used to determine the hemodynamic parameters at each site:

Vessel diameter, $\mathrm{mm}$

Cross-sectional area $(\mathrm{CSA})=(\mathrm{D} / 2) 2 \times \pi, \mathrm{mm}^{2}$

Peak systolic velocity (PSV), $\mathrm{cm} / \mathrm{s}$

End diastolic velocity (EDV), $\mathrm{cm} / \mathrm{s}$

Resistive index $(\mathrm{RI})=(\mathrm{PSV}-\mathrm{EDV}) / \mathrm{PSV}$

Pulsatility index (PI)

Mean flow velocity (MV) $\mathrm{cm} / \mathrm{s}$

Blood flow volume $(\mathrm{BFV})=\mathrm{CSA} \times \mathrm{MV}, \mathrm{mL} / \mathrm{s}$.

To standardize measurements of PSV of $\mathrm{v}$. vertebralis, some segment of it in the projection between the transverse spines C5-C6 was selected.

The acupuncture influence was carried out with disposable fine stainless steel needles of two types (diameter $0.30 \mathrm{~mm}$, length $40 \mathrm{~mm}$ ) and (diameter 0.25 $\mathrm{mm}$, length $25 \mathrm{~mm}$ ). The duration of the session was 20 minutes, after which the blood flow parameters were re-evaluated immediately.

Since the main complaints in all patients were headache and/or stiffness in the neck region, a standardized number of nonspecific acupoints namely GB12, GB20, HT7, PC7, LI4, LI10, ST36, ST40, SP6, LR3 were selected. All patients had all the points punctured bilaterally.

The research protocol was prepared in accordance with international ethical standards (Declaration of Helsinki) and approved on 03 February 2017 by local Ethical Committee.

Statistical data were processed according to Student's criterion for dependent and independent samples and one-factor dispersion analysis using the statistical package "Microsoft Office Excel 2007" and "Statistics for Windows 6.0".

\section{Results and Discussion}

The analysis of the acupuncture effects was evaluated as follows: 1 -influence on the venous system, 2-influence on the vertebro-basilar arteries, 3 -influence on the carotid arteries.

\subsection{Influence on the Venous System}

Analysis of venous outflow indices with Student's test showed a reliable change in linear velocities in v.vertebralis and v.Rosenthal after the acupuncture session in Table 1.

So, as we can see, there were reliable $(p<0.05)$ post acupuncture changes in blood flow of v.vertebralis and v.Rosenthal. Their velocities presented in Figs. 2 and 3.

Since the average values norm of v.vertebralis PSV is $24 \pm 12 \mathrm{~cm} / \mathrm{s}$ [24], the patients before acupuncture had both pathologically accelerated and slowed velocities. Attention was paid to the fact that acupuncture revealed a modulating effect on venous blood flow. For example, at a maximum PSV of 106 $\mathrm{cm} / \mathrm{s}$ before, we received $96 \mathrm{~cm} / \mathrm{s}$ after the acupuncture, and vice versa-minimum PSV of $7.5 \mathrm{~cm} / \mathrm{s}$ we received $30 \mathrm{~cm} / \mathrm{s}$ after the session.

We also analyzed in Fig. 4 the dependence of the difference between the linear velocity of v.vertebralis before and after the procedure (delta) and age dependence. The variability of delta increases with the age; even visually, the corridor of possible values expand after 55 years.

Table 1 Linear velocities dynamics in v.vertebralis and v.Rosenthal before and after the acupuncture.

\begin{tabular}{llllllll}
\hline \multirow{2}{*}{ Vessels } & \multicolumn{3}{c}{ Mean } & \multicolumn{2}{c}{ Std. dev. } & \multirow{2}{*}{ Std. dev. } & $t$ \\
\cline { 2 - 8 } & Before & After & Before & After & & $p$ \\
\hline v.vertebralis & 39.233 & 35.717 & 21.636 & 19.670 & 13.291 & 2.014 & $0.049 *$ \\
v.Rosenthal & 17.856 & 16.741 & 4.331 & 3.963 & 3.632 & 3.632 & $0.001 *$ \\
\hline
\end{tabular}

$* p<0.05$. 

from Cerebrovascular Pathology with Duplex Ultrasound Doppler Imaging

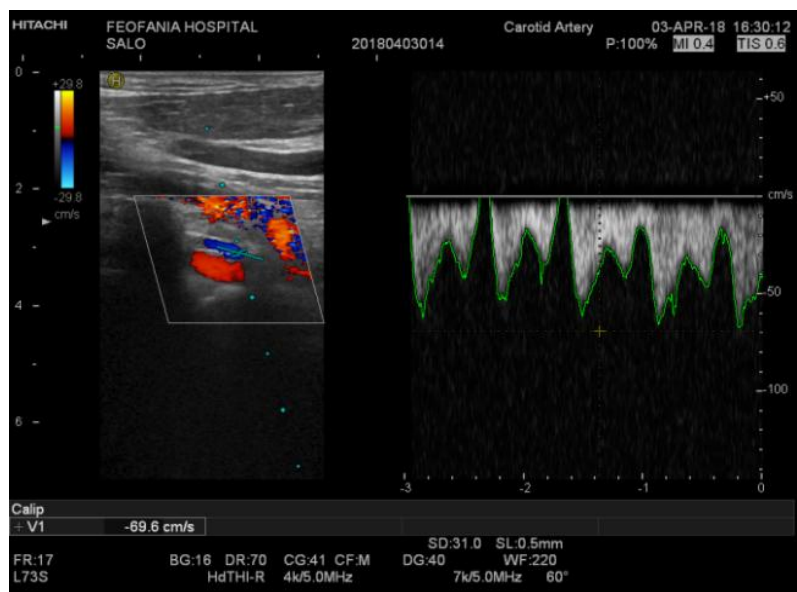

(a)

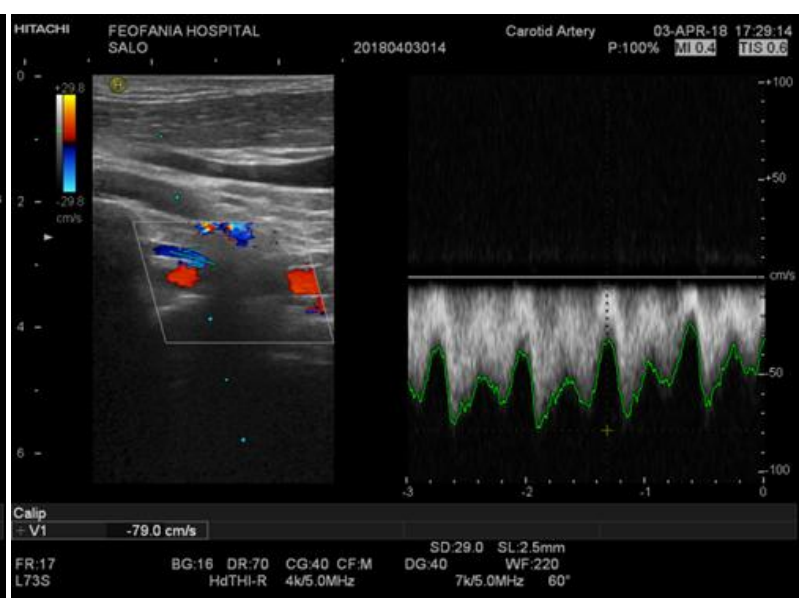

(b)

Fig. 2 V.vertebralis before (a) and after (b) 20 minutes acupuncture session.

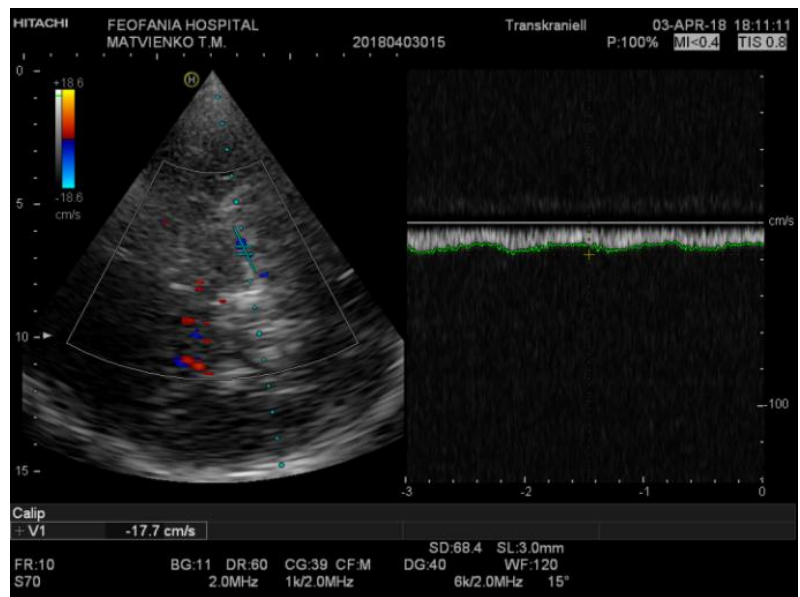

(a)

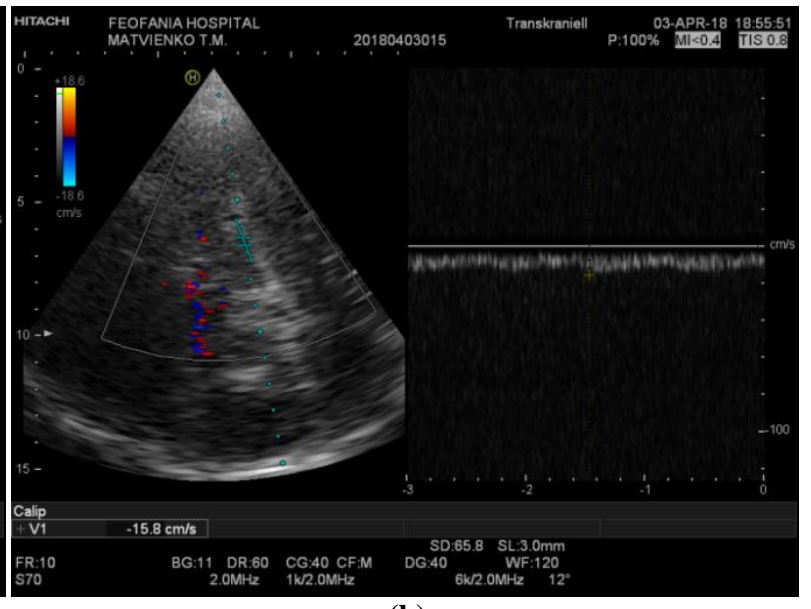

(b)

Fig. 3 V.Rosenthal before (a) and after (b) 20 minutes acupuncture session.

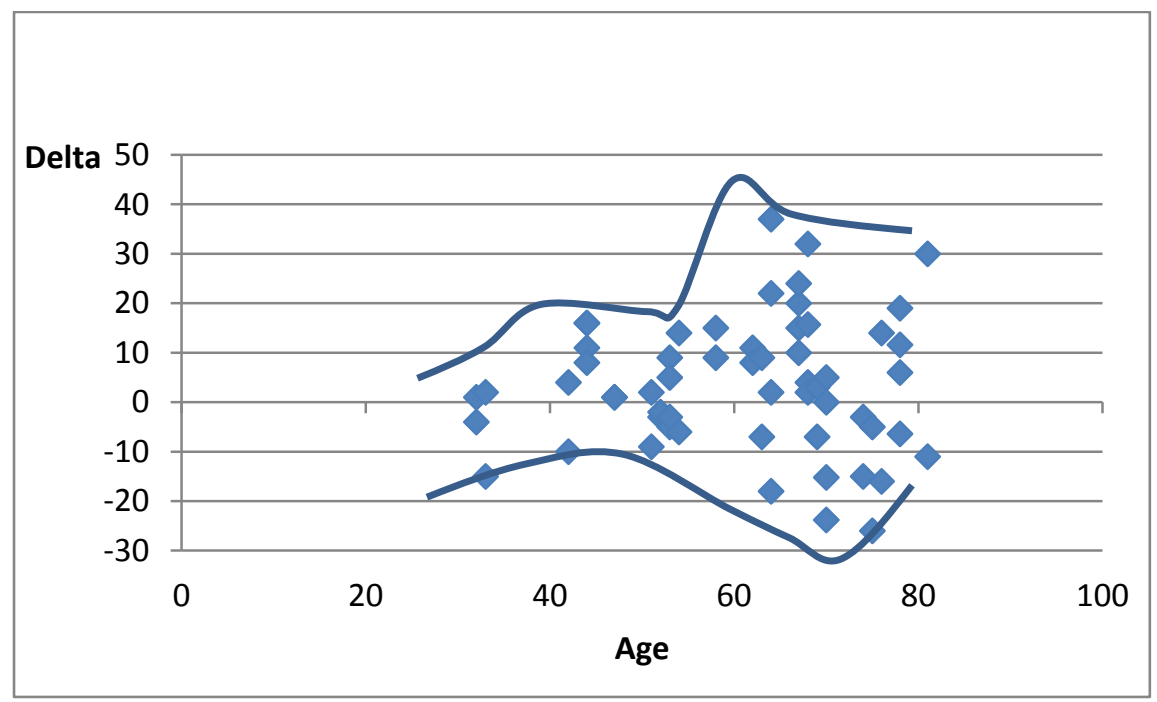

Fig. 4 Age dependence of velocity delta of v.vertebralis. 


\subsection{Influence on the Vertebro-Basilar Arteries}

The following parameters of the arterial blood flow in Table 2 were responded to the acupuncture session: PI of a.vertebralis, PSV of a.vertebralis in extra (V2) and intracranial (V4) segments.

Thus, statistically reliable $(p<0.05)$ data on PI of a.vertebralis and PSV of a.vertebralis in extra and intracranial segments changed after 20-minute acupuncture session. Fig. 5 shows the intracranial part of a.vertebralis (V4).

\subsection{Influence on Carotid Arteries}

According to Table 3 only RI of a.carotis interna revealed a reliable $(p<0.05)$ change, indicating the decreasing in peripheral resistance and improvement of blood flow in a.carotis interna.

One-factor dispersion analysis in Table 4 showed a tendency $(p<0.1)$ to decrease RI in a.cerebri media (ACM) after one acupuncture session. It is likely that longer follow-up and subsequent acupuncture sessions will result in more optimistic outcomes.

For the further study we divided our groups into two subgroups: 1-patients who had a stroke in anamnesis-so called "poststroke" group and 2 -patients who had no stroke in anamnesis, so-called a "nonstroke" one. Table 5 shows reliable indicators of the blood flow decrease of v.Rosenthal $(p<0.05)$ in the "poststroke" group.

Table 2 Haemodynamic parameters of blood flow in a.vertebralis, a.basilaris and a.cerebri posterium before and after the acupuncture session with Student's test.

\begin{tabular}{|c|c|c|c|c|c|c|c|}
\hline \multirow{2}{*}{ Vessels } & \multicolumn{2}{|c|}{ Mean } & \multicolumn{2}{|c|}{ Std. dev. } & \multirow{2}{*}{-Std. dev. } & \multirow{2}{*}{$t$} & \multirow{2}{*}{$p$} \\
\hline & Before & After & Before & After & & & \\
\hline a.vertebralis V2 PSV & 43.100 & 41.367 & 9.264 & 8.567 & 6.415 & 2.093 & $0.041 *$ \\
\hline a.vertebralis V2 EDV & 12.828 & 12.433 & 4.179 & 4.180 & 3.053 & 1.002 & 0.320 \\
\hline a.vertebralis RI & 0.710 & 0.705 & 0.147 & 0.123 & 0.112 & 0.361 & 0.720 \\
\hline a.vertebralis PI & 0.521 & 1.366 & 0.632 & 0.485 & 0.555 & 2.081 & $0.042 *$ \\
\hline a.cerebri posterior EDV & 28.407 & 28.254 & 8.910 & 8.891 & 4.246 & 0.276 & 0.784 \\
\hline a.vertebralis V4 PSV & 44.383 & 46.967 & 14.940 & 15.617 & 7.857 & -2.546 & $0.014 *$ \\
\hline a.vertebralis V4 EDV & 19.633 & 20.433 & 7.816 & 7.597 & 4.157 & -1.490 & 0.141 \\
\hline a.basilaris PSV & 65.533 & 63.767 & 20.882 & 17.518 & 10.975 & 0.882 & 0.385 \\
\hline a.basilaris EDV & 27.433 & 26.9 & 9.024 & 9.091 & 4.562 & 0.640 & 0.527 \\
\hline
\end{tabular}

$* p<0.05$.

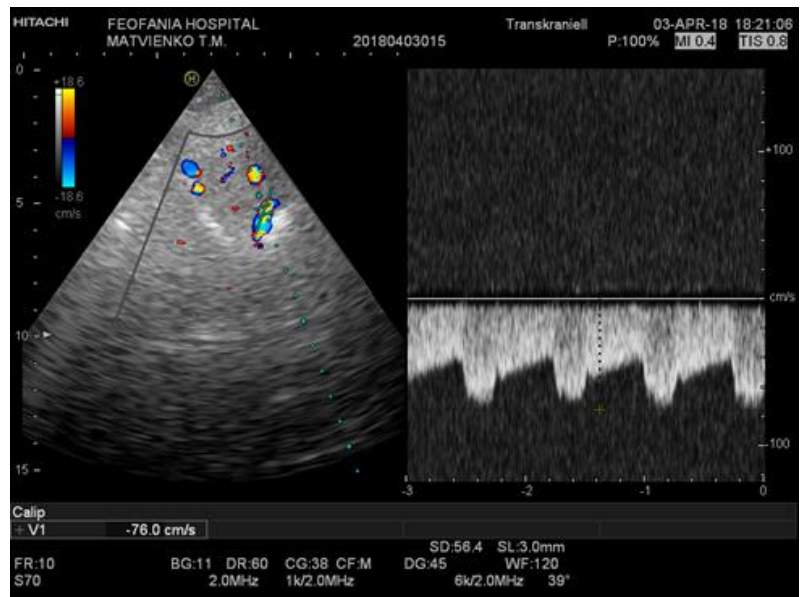

(a)

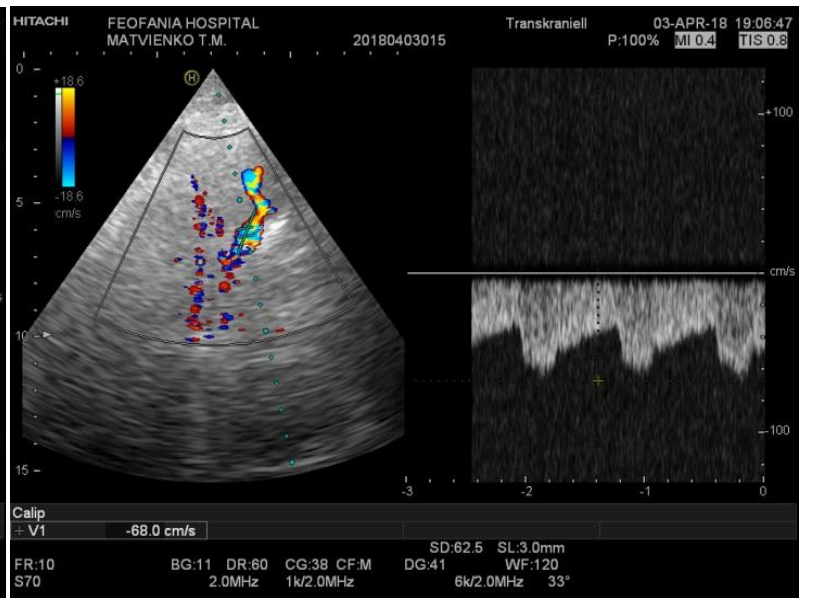

(b)

Fig. 5 Intracranial part of a.vertebralis (V4) before the acupuncture (a) and after (b). 

from Cerebrovascular Pathology with Duplex Ultrasound Doppler Imaging

Table 3 Haemodynamic parameters of blood flow in a.carotis interna and a.cerebri media before and after the acupuncture session according to Student's test.

\begin{tabular}{|c|c|c|c|c|c|c|c|}
\hline \multirow{2}{*}{ Vessels } & \multicolumn{2}{|c|}{ Mean } & \multicolumn{2}{|c|}{ Std. dev. } & \multirow{2}{*}{-Std. dev. } & \multirow{2}{*}{$t$} & \multirow{2}{*}{$p$} \\
\hline & Before & After & Before & After & & & \\
\hline a.carotis interna PSV & 70.964 & 68.982 & 17.042 & 20.398 & 14.314 & 1.036 & 0.305 \\
\hline a.carotis interna EDV & 23.679 & 22.821 & 8.240 & 8.231 & 5.382 & 1.192 & 0.238 \\
\hline a.carotis interna RI & 0.662 & 0.633 & 0.089 & 0.090 & 0.082 & 2.615 & $0.012 *$ \\
\hline a.carotis interna PI & 1.276 & 1.250 & 0.335 & 0.348 & 0.268 & 0.715 & 0.478 \\
\hline a.cerebri media PSV & 98.231 & 100.289 & 41.072 & 42.745 & 15.305 & -0.969 & 0.337 \\
\hline a.cerebri media EDV & 40.885 & 41.192 & 21.815 & 23.605 & 8.113 & -0.273 & 0.786 \\
\hline a.cerebri media MV & 64.673 & 63.233 & 30.489 & 34.871 & 17.039 & 0.610 & 0.545 \\
\hline a.cerebri media RI & 0.557 & 0.568 & 0.080 & 0.105 & 0.115 & -0.631 & 0.531 \\
\hline a.cerebri media PI & 0.895 & 0.908 & 0.234 & 0.221 & 0.192 & -0.476 & 0.636 \\
\hline
\end{tabular}

$* p<0.05$.

Table 4 One-factor dispersion analysis of blood flow in a.cerebri media.

\begin{tabular}{lllllllll}
\hline & SS & df & MS & SS & df & MS & \\
\cline { 2 - 8 } & Effect & Effect & Effect & Error & Error & Error & $F$ & $p$ \\
\hline ACM_PSV before & 128.788 & 1 & 128.788 & $85,904.44$ & 50 & $1,718.089$ & 0.075 & 0.785 \\
ACM_EDV before & 40.162 & 1 & 40.162 & $24,231.15$ & 50 & 484.623 & 0.083 & 0.775 \\
ACM_MV before & 153.697 & 1 & 153.697 & $47,251.75$ & 50 & 945.035 & 0.163 & 0.688 \\
ACM_RI_before & $7.99 E-05$ & 1 & $7.99 \mathrm{E}-05$ & 0.287 & 45 & 0.006 & 0.013 & 0.911 \\
ACM_PI_before & 0.012 & 1 & 0.012 & 2.787 & 50 & 0.056 & 0.221 & 0.640 \\
ACM_PSV_after & 293.357 & 1 & 293.357 & $22,591.63$ & 54 & 418.363 & 0.701 & 0.406 \\
ACM_EDV_after & 11.006 & 1 & 11.006 & $3,715.208$ & 54 & 68.800 & 0.160 & 0.691 \\
ACM_PSV after & 379.659 & 1 & 379.659 & $92,805.01$ & 50 & $1,856.1$ & 0.204 & 0.653 \\
ACM_EDV after & 28.719 & 1 & 28.719 & $28,389.36$ & 50 & 567.787 & 0.050 & 0.823 \\
ACM_MV after & 882.549 & 1 & 882.55 & $61,133.65$ & 50 & $1,222.673$ & 0.722 & 0.399 \\
ACM_RI_after & 0.035 & 1 & 0.035 & 0.476 & 45 & 0.011 & 3.287 & $0.076 * *$ \\
ACM_PI_after & 0.001 & 1 & 0.007 & 2.486 & 50 & 0.050 & 0.135 & 0.714 \\
ACM_PSV_delta & 366.218 & 1 & 366.218 & $15,959.77$ & 50 & 319.195 & 1.147 & 0.289 \\
ACM_EDV_delta & 75.057 & 1 & 75.057 & $24,616.56$ & 50 & 492.331 & 0.152 & 0.698 \\
ACM_MV_delta & $1,377.784$ & 1 & $1,377.784$ & $38,513.39$ & 50 & 770.268 & 1.789 & 0.187 \\
ACM_RI_delta & $1,604.387$ & 1 & $1,604.387$ & $21,577.92$ & 45 & 479.509 & 3.346 & $0.074 * *$ \\
ACM_PI_delta & 116.589 & 1 & 116.589 & $16,120.68$ & 50 & 322.414 & 0.362 & 0.550 \\
\hline ** $<$ <0.1 & & & & & & &
\end{tabular}

** $p<0.1$

Table 5 Analysis of linear velocity dynamics in v.vertebralis and v.Rosenthal before and after the acupuncture with Student's test in "poststroke" patients.

\begin{tabular}{|c|c|c|c|c|c|c|c|}
\hline \multirow{2}{*}{ Vessels } & \multicolumn{2}{|c|}{ Mean } & \multicolumn{2}{|c|}{ Std. dev. } & \multirow{2}{*}{ Std. dev. } & \multirow{2}{*}{$t$} & \multirow{2}{*}{$p$} \\
\hline & Before & After & Before & After & & & \\
\hline v.vertebralis & 34.568 & 29.845 & 17.983 & 15.279 & 13.980 & 1.584 & 0.13 \\
\hline v.Rozenthal & 17.363 & 15.683 & 3.356 & 2.460 & 2.286 & 3.599 & $0.002 *$ \\
\hline
\end{tabular}

$* p<0.05$.

"Nonstroke" group presented in Table 6 showed only a tendency to decrease the linear velocity in $\mathrm{v}$. Rosenthal $(p>0.1)$, which grows to the reliable ( $p<$ $0.05)$ with the growing number of patients demonstrated in Table 1.
One-factor dispersion analysis of blood flow in v.vertebralis and v.Rosenthal reveals the following in Table 7. The linear velocities of v.vertebralis and $v$. Rosenthal in the different groups did not differ before the acupuncture $(p>0.05)$. However, the response on 
Table 6 Analysis of linear velocity dinamics in v.vertebralis and v. Rosenthal before and after the acupuncture with Student's test in "nonstroke" patients.

\begin{tabular}{|c|c|c|c|c|c|c|c|}
\hline \multirow{2}{*}{ Vessels } & \multicolumn{2}{|c|}{ Mean } & \multicolumn{2}{|c|}{ Std. dev. } & \multirow{2}{*}{ Std. dev. } & \multirow{2}{*}{$t$} & \multirow{2}{*}{$p$} \\
\hline & Before & After & Before & After & & & \\
\hline v.vertebralis & 42.083 & 39.306 & 23.373 & 21.334 & 12.997 & 1.282 & 0.208 \\
\hline v.Rozenthal & 18.194 & 17.466 & 4.909 & 4.622 & 2.361 & 1.825 & $0.077 * *$ \\
\hline
\end{tabular}

Table 7 One-factor dispersion analysis of blood flow in v.vertebralis and v. Rosenthal.

\begin{tabular}{lllllllll}
\hline & SS & df & MS & SS & df & MS & & \\
\cline { 2 - 8 } & Effect & Effect & Effect & Error & Error & Error & $F$ & $p$ \\
\hline v.vertebralis before & 771.21 & 1 & 771.21 & $2,5911.5$ & 56 & 462.705 & 1.667 & 0.202 \\
v.Rozenthal before & 9.850 & 1 & 9.850 & $1,078.255$ & 57 & 18.917 & 0.521 & 0.473 \\
v.vertebralis after & $1,222.049$ & 1 & $1,222.049$ & $20,832.27$ & 56 & 372.005 & 3.285 & $0.075^{* *}$ \\
v.Rozenthal after & 45.230 & 1 & 45.230 & 865.612 & 57 & 15.186 & 2.978 & $0.090^{* *}$ \\
Delta v.vertebralis & 51.655 & 1 & 51.655 & $10,017.02$ & 56 & 178.875 & 0.289 & 0.593 \\
\hline
\end{tabular}

** $p<0.1$

Table 8 Comparative analysis of mean flow velocity (MV) and blood flow volume (BFV) of a.vertebralis in "nonstroke" patients.

\begin{tabular}{|c|c|c|c|c|c|c|c|}
\hline \multirow{2}{*}{ Vessels } & \multicolumn{2}{|c|}{$\mathrm{m}$} & \multicolumn{2}{|c|}{ Std Dev } & \multirow{2}{*}{ Std Dev } & \multirow{2}{*}{$\mathrm{t}$} & \multirow{2}{*}{$\mathrm{p}$} \\
\hline & before & after & before & after & & & \\
\hline a.vertebralis MV & 21.513 & 24.171 & 5.985 & 8.931 & 9.522 & -1.579 & 0.125 \\
\hline a.vertebralis BFV & 17.225 & 19.864 & 6.996 & 9.501 & 7.869 & -1.897 & 0.067 \\
\hline
\end{tabular}

Table 9 Comparative analysis of mean flow velocity (MF) and blood flow volume (BFV) of a.vertebralis in "poststroke" patients.

\begin{tabular}{|c|c|c|c|c|c|c|c|}
\hline \multirow{2}{*}{ Vessels } & \multicolumn{2}{|c|}{ Mean } & \multicolumn{2}{|c|}{ Std. dev. } & \multirow{2}{*}{ Std. dev. } & \multirow{2}{*}{$t$} & \multirow{2}{*}{$p$} \\
\hline & Before & After & Before & After & & & \\
\hline a.vertebralis MV & 21.745 & 21.336 & 7.457 & 7.198 & 4.189 & 0.468 & 0.644 \\
\hline a.vertebralis BFV & 17.401 & 16.839 & 7.197 & 7.161 & 3.318 & 0.811 & 0.426 \\
\hline
\end{tabular}

acupuncture effects among representatives of different groups was different.

The mean velocity delta of v.vertebralis before and after the procedure in the group of "poststroke" patients was $34.57-29.85=4.74 \mathrm{~cm} / \mathrm{s}$ (Table 5). The mean velocity delta of v.vertebralis before and after the procedure in "nonstroke" group was $42.08-39.31$ $=2.77 \mathrm{~cm} / \mathrm{c}$ (Table 6). So, "poststroke" group reacts to the procedure 1.7 times more actively than "nonstroke" group.

A comparative analysis of the difference in the response of arterial vessels to acupuncture influence in the group of "nonstroke" patients showed in Tables 8 and 9 a tendency to the change $(p=0.067)$ of the volume flow rate of a.vertebralis compared to "poststroke" group.

\section{Conclusion}

Thus, as a result of the study, the following conclusions should be made:

For the first time the evaluation of venous blood flow by duplex ultrasound Doppler imaging after acupuncture reliably $(p<0.05)$ revealed the changes in linear blood velocity of v.vertebralis and v.Rosenthal in the studied patients.

The evaluation of the variability of delta values of v.vertebralis revealed the age dependency and expansion of the corridor of possible values after 55 years.

The evaluation of the arterial blood flow of vertebrobasilar vessels using duplex ultrasound Doppler imaging after acupuncture showed reliable ( $p$ $<0.05)$ changes in the pulsatility index (PI) and peak 

from Cerebrovascular Pathology with Duplex Ultrasound Doppler Imaging

systolic velocity (PSV) in extracranial (V2) and intracranial (V4) parts of a.vertebralis.

The assessment of arterial blood flow in the carotid vessels (a.carotis interna and a.cerebri media) reliably $(p<0.05)$ demonstrated the effect of acupuncture on RI of a.carotis interna. RI of ACM revealed the tendency to change after the acupuncture.

A comparative analysis of two subgroups of patients: "poststroke" and "nonstroke" revealed differences in the response to the acupuncture. Reliable $(p<0.05)$ values of blood flow were found only in v.Rosenthal of "poststroke" patients. "Nonstroke" patients demonstrated only the tendency to the change of this parameter, as well as the tendency to the change of the volume velocity of blood flow of a.vertebralis. In general, the "poststroke" group responded to the procedure 1.7 times more actively than "nonstroke" one.

So, based on the results obtained after one general acupuncture session, it would be advisable to consider wider the impact of acupuncture on the arteries and veins of the head and neck. This promising direction of development of complementary methods will improve the results of treatment and rehabilitation of the patients with vascular pathology of the brain.

\section{Conflict of Interests}

The authors have no conflict of interests.

\section{References}

[1] Xia, Y. 2012. Current Research in Acupuncture. Springer Science \& Business Media.

[2] Hempel, S., Taylor, S., Solloway, M., Miake-Lye, I., Beroes, J., Shanman, R., et al. 2014. Evidence Map of Acupuncture VAESP Project. ID: 05-226.

[3] Ma, S. X. 2004. "Neurobiology of Acupuncture: Toward CAM." Evidence-Based Complementary Alternative Medicine $\quad 1 \quad$ (1): 41-7. http://dx.doi.org/10.1093/ecam/neh017.

[4] Kawakita, K., and Okada, K. 2014. "Acupuncture Therapy: Mechanism of Action, Efficacy, and Safety: A Potential Intervention for Psychogenic Disorders?" $\begin{array}{llll}\text { Biopsychosocial } \quad \text { Medicine } \quad 8 & \text { (1): } & \text { 1-7. }\end{array}$ doi:10.1186/1751-0759-8-4.

[5] MacPherson, H., Hammerschlag, R., Coeytaux, R., Davis,
R., Harris, R., Kong, J., et al. 2016. "Unanticipated Insights into Biomedicine from the Study of Acupuncture." The Journal of Alternative and Complementary Medicine 22 (2): 101-7. doi:10.1089/acm.2015.0184.

[6] Vodyanoy, V., Pustovyy, O., Globa, L., and Sorokulova, I. 2015. "Primo-Vascular System as Presented by Bong Han Kim." Evidence-Based Complementary and Alternative Medicine. Article ID 361974, 17 pages. http://dx.doi.org/10.1155/2015/361974.

[7] Soh, K. S., Kang, K., and Harrison, D. 2012. The Primo Vascular System: Its Role in Cancer and Regeneration. Springer.

[8] Stefanov, M., Potroz, M., Kim, J., Cha, R., and Nam, M. 2013. "The Primo Vascular System as a New Anatomic System." Journal of Acupuncture and Meridian Studies 6 (6): 331-8. https://doi.org/10.1016/j.jams.2013.10.001.

[9] Deng, S., Zhao, X., Du, R., He, S., Wen, Y., Huang, L., et al. 2015. "Is Acupuncture No More Than a Placebo? Extensive Discussion Required about Possible Bias." Experimental and Therapeutic Medicine 4 (10): 1247-52. doi:10.3892/etm.2015.2653.

[10] Wong, L. Y., Chung Leung, P., and Zhang, L. 2015. "Placebo Acupuncture in an Acupuncture Clinical Trial. How Good Is the Blinding Effect?" Journal of Acupuncture and Medridian Studies 8 (11): 40-3. https://doi.org/10.1016/j.jams.2014.10.010.

[11] Kathleen, K., Hui, S., Napadow, V., Liu, J., Li, M., Marina, O., et al. 2010. "Monitoring Acupuncture Effects on Human Brain by fMRI." Journal of Visualized Experiments 38: 1190. doi:10.3791/1190.

[12] Napadow, V., Liu, L., Li, M., Kettner, N., Ryan, A., Kwong, K., et al. 2007. "Somatosensory Cortical Plasticity in Carpal Tunnel Syndrome Treated by Acupuncture." Human Brain Mapping 28 (3): 159-71. PMID: 16761270 DOI:10.1002/hbm.20261.

[13] Takayama, S., Seki, T., Watanabe, M., Monma, Y., Yang, S., Sugita, N., et al. 2010. "Briief Effect of Acupuncture on the Peripheral Arterial System of the Upper Limb and Systemic Hemodynamics in Humans." Journal of Alternative and Complementary Medicine 16 (7):707-13. doi: 10.1089/acm.2009.0355.

[14] Takayama, S., Seki, T., Nakazawa, T., Aizawa, N., Takahashi, S., Watanabe, M., et al. 2010. "Short-Term Effects of Acupuncture on Open-Angle Glaucoma in Retrobulbar Circulation: Additional Therapy to Standard Medication." Evidence Based Complementary and Alternative Medicine Article ID 157090, 6 pages. http://dx.doi.org/10.1155/2011/157090.

[15] Takayama, S., Seki, T., Watanabe, M., et al. 2011. "Changes of Blood Flow Volume in the Superior Mesenteric Artery and Brachial Artery with Abdominal Thermal Stimulation." Evidence-Based Complementary 

from Cerebrovascular Pathology with Duplex Ultrasound Doppler Imaging

and Alternative Medicine Article ID 214089, 10 pages. PMCID: PMC3095448 DOI: 10.1093/ecam/nep110.

[16] Takayama, S., Seki, T., Sugita, N., Konno, S., Arai, H., Saijo, Y., et al. 2010. "Radial Artery Hemodynamic Changes Related to Acupuncture." Explore 6 (2): 100-5. https://doi.org/10.1016/j.explore.2009.12.001.

[17] Takayama, S., Watanabe, M., Kusuyama, H., Nagase, S., Seki, T., Nakazawa, T., and Yaegashi, N. 2012. "Evaluation of the Effects of Acupuncture on Blood Flow in Humans with Ultrasound Color Doppler Imaging." Evidence-Based Complementary and Alternative Medicine Article ID 513638, 8 pages. http://dx.doi.org/10.1155/2012/513638.

[18] Kim, S.-Y., Min, S., Lee, H., Cheon, S., Zhang, X., Park, J., et al. 2016. "Changes of Local Blood Flow in Response to Acupuncture Stimulation: A Systematic Review." Evidence-Based Complementary and Alternative Medicine 11 pages. Article ID 9874207 http://dx.doi.org/10.1155/2016/9874207.

[19] Min, S., Lee, H., and Kim, S.-Y. 2015. "Local Changes in Microcirculation and the Analgesic Effects of Acupuncture: A Laser Doppler Perfusion Imaging Study." Journal of Alternative and Complementary Medicine 21 (1): 46-52. doi:10.1089/acm.2013.0442.

[20] Kovalenko, O., Mikhal, G., and Polovka, L. 2011. "The Evaluation of Some Head Acupuncture Points Effects on Cerebral Hemodynamic with Doppler Ultrasound
Imaging." Collection of NMAPE Works 20 (2): 262-75.

[21] Intracranial Cerebrovascular Evaluation Transcranial Doppler (Non-Imaging) and Transcranial Duplex Imaging (TCDI). Professional Performance Guidelines. Society for Vascular Ultrasound USA.

[22] Kulikov, V., Kirsanov, P., and Zasorin, S. 2012. Standards of Duplex Ultrasound Vessels. Barnaul Altay State Medical University.

[23] Lelyuk, V., and Lelyuk, S. 2003. Ultrasound Angiology. Moscow: Real Time.

[24] Csiba, L. 2016. Manual of Neurosonology. Cambridge: Cambridge University Press.

[25] Zavoreo, I., Basic-Kes, V., and Motovino, L. 2013. "Cerebral Venous Circulatory System Evaluation by Ultrasonography." Acta Clinica Croatia. 52 (2): 203-11.

[26] Zaniewski, M., Kostecki, W., Kuczmik, J., Kuczmik, W., Ziaja, D., Opala, G., et al. 2013. "Neck Duplex Doppler Ultrasound Evaluation for Assessing Chronic Cerebrospinal Venous Insufficiency in Multiple Sclerosis.” Phlebology: The Journal of Venous Disease 28: 24-31. doi: 10.1258/phleb.2011.011070.

[27] Jandaghi Babaei, A., Amanian, D., Roudbari, S., Kanafi, A., and Pourghorban, R. 2014. "Evaluation of Hemodynamic Properties of Cerebral Venous Drainage in Patients with Multiple Sclerosis: A Case Control Study." Polish Journal of Radiology. 79: 323-7. doi:10.12659/PJR.890690. 